\title{
BLOOD LOSS IN TKA UNDER TOURNIQUET CONTROL, WILL IT LEAD TO HAEMODYNAMIC INSTABILITY
}

\author{
B. Narendra Reddy¹, P. Anil Babu²
}

${ }^{1}$ Associate Professor, Department of Orthopaedics, NRI Medical College, Chinakakani, Guntur, Andhra Pradesh, India. ${ }^{2}$ Assistant Professor, Department of Orthopaedics, GMC, Guntur, Andhra Pradesh, India.

\section{ABSTRACT}

\section{BACKGROUND}

Total knee arthroplasty is one of the major surgeries, where considerable haemorrhage should be expected leading to haemodynamic instability and subsequent delay in ambulation and recovery. The soft tissue release and bone cuts required for TKA are the major sites from which haemorrhage is expected.

\section{MATERIALS AND METHODS}

Our study is to know the blood loss following TKA in our case series, and at what severity it can lead to postoperative blood transfusions and whether it can lead to haemodynamic instability or not with the given perioperative protocol. Blood loss is analysed in the groups with above and below average $\mathrm{Hb}$ and PCV with continuous tachycardia and hypotension.

\section{RESULTS}

Out of 168 patients in study group requirement for blood transfusion is for 93 cases, requiring transfusion with tachycardia and fall in BP and 5 cases requiring transfusion in both the below-above mean group of $\mathrm{Hb}$ and PCV respectively.

\section{CONCLUSION}

The haematocrit changes seen postoperatively are dependent on the haemodilution, going by the drop in Hb and PCV seen in both groups undergoing the same surgery with same indication, same approach, same surgeon and implant, even when the Hb and PCV levels are normal.

\section{KEYWORDS}

Total Knee Arthroplasty, Blood Loss, Haemodynamic Instability, Blood Transfusion.

HOW TO CITE THIS ARTICLE: Reddy BN, Babu PA. Blood loss in TKA under tourniquet control, will it lead to haemodynamic instability. J. Evolution Med. Dent. Sci. 2017;6(46):3582-3585, DOI: 10.14260/Jemds/2017/772

\begin{abstract}
BACKGROUND
Total knee arthroplasty is one of the major surgeries, where considerable haemorrhage should be expected leading to haemodynamic instability and subsequent delay in ambulation and recovery. The soft tissue release and bone cuts required for TKA are the major sites from which haemorrhage is expected. Moreover, anticoagulants given to prevent deep vein thrombosis can cause added blood loss. There is a consensus in the literature that most of the patients require careful monitoring to avoid perioperative complications like haemorrhage. The intraoperative blood loss can be assessed by weighing the mops and collection into the suction containers in surgeries performed without tourniquet. The loss of blood becomes evident after surgery performed with tourniquet with collection into the suction drain container. Once the surgical wound is closed, the blood loss detected by the collection into container, the loss of volume as well as changes in the haematocrit can be measured.
\end{abstract}

Financial or Other, Competing Interest: None.

Submission 30-04-2017, Peer Review 27-05-2017,

Acceptance 01-06-2017, Published 08-06-2017.

Corresponding Author:

Dr. P. Anil Babu,

D. No. 5-54-120,

101 Suryodaya Residency,

6/18 Brodipet,

Guntur-522002,

Andhra Pradesh, India.

E-mail: anilpbabu@gmail.com

DOI: $10.14260 /$ jemds $/ 2017 / 772$
The amount of blood loss in TKA varies from underlying cause for arthritis, tourniquet time, gender and surgery duration. ${ }^{1}$

The body mass index did not influence either the intra-operative or the post-operative blood loss. Intra-operative release of the tourniquet causes more blood loss compared with keeping the tourniquet inflated until the application of a compressive bandage at the end. The blood loss can result in haemodynamic instability, which can be predicted by drop in Hb levels and PCV. But the changes or drop in the levels can be due to redistribution of the volume or haemodilution.

The visible blood loss in postoperative period may not be the real blood loss, in fact it is a part of total blood loss. Hidden blood loss is seen in TKA, where haemorrhage occurs into the tissue planes dissected for the surgery. ${ }^{2}$

Insertion of a constrained TKA resulted in a statistically significant increase in blood loss. Preoperative diagnosis, anaesthetic technique, revision arthroplasty, patellofemoral arthroplasty and tourniquet technique do not statistically affect the blood loss. ${ }^{2}$

The bulk of the blood loss is collected postoperatively in the suction drain; the PCV and $\mathrm{Hb}$ levels often indicate impending haemodynamic instability. ${ }^{3}$ There are postoperative factors, which can add on to the surgical procedure as contributing factors to the pre-existing tendency to bleed following surgery. They are hypertension and anticoagulants. ${ }^{4}$

An individualised strategy based on patient's specific risk factors, anticipated blood loss and comorbidities are useful in 
achieving this aim. Multiple blood conservation strategies are available in the preoperative, intraoperative and postoperative periods, and can be employed in various combinations. Recent literature has highlighted the importance of preoperative $\mathrm{Hb}$ optimisation, minimising blood loss and evidence-based transfusion guidelines. Given TKA is an elective procedure, a zero-allogeneic blood transfusion rate should be the aim and an achievable goal.

Intraoperative blood salvage is not effective in preventing allogeneic blood transfusion in patients with a preoperative haemoglobin level < $120 \mathrm{~g} / \mathrm{L}$. It should be combined with preoperative optimisation of the haemoglobin level or use of tranexamic acid. ${ }^{5}$ The blood loss in TKA becomes a potential complication, if it is not properly managed. The planning should begin in the preoperative period, intra- and perioperative periods to take specific measures to control it.

\section{MATERIALS AND METHODS}

Our study is to know the blood loss following TKA in our case series, and at what severity it can lead to postoperative blood transfusions, and whether it can lead to haemodynamic instability or not with the given peri-operative protocol. Our study is designed as a cross-sectional, prospective study to know the need for blood transfusions in postoperative period following TKA. The study is designed to detect the haemodynamic instability in the patients developing tachycardia, hypotension, drop in HB and PCV levels following TKA. Each of these changes is further monitored to know whether they are corrected by IV fluids alone or getting further deteriorated, necessitating compatible blood transfusions.

Our study group consists of 168 primary osteoarthritis of knee joint patients. All the patients were evaluated for their fitness for surgery. The surgery is performed by a single surgeon with single technique, under tourniquet control throughout surgery with posterior stabilised design of implant.

The inclusion criteria are Grade 3 or 4 primary osteoarthritis of knee joint, haemoglobin level of $10 \mathrm{gm} \%$ and above, controlled hypertension and normal coagulation profile. The exclusion criterion are patients requiring preoperative blood transfusions, uncontrolled hypertension, anticoagulant usage and secondary osteoarthritis.

The surgery is done with a midline incision for skin and subcutaneous tissue. A medial parapatellar incision is given for arthrotomy. This incision produces 8 to $13 \mathrm{cms}$ of surgical wound. The bone cuts are taken. Femoral hole is plugged with bone graft. Implantation is done over bone cement. The wounds are closed with a suction drain. A mild compression bandage is applied. Tourniquet is released.

The patient is given an intrareticular cocktail consisting of Bupivacaine $0.5 \% 5 \mathrm{~mL}$, tranexamic acid $500 \mathrm{mg}$, DepoMedrol $80 \mathrm{mg}$, Cefuroxime $1 \mathrm{gm}$ given at a depth of $3 \mathrm{~mm}$ in the surgical wound.

Postoperatively, patients are given $100 \mathrm{~mL}$ of NS per hour on day one and $80 \mathrm{~mL}$ per hour in the second postoperative day. The collection into the suction drain container is measured. The drain is removed on third postoperative day. The drain container is emptied and then connected; if the collection is more than $400 \mathrm{~mL}$, to maintain the suction pressure. The patients are monitored for haemodynamic stability with pulse and blood pressure.
Postoperatively, all the cases are given low molecular weighted heparin till the patient starts bearing weight on third or fourth postoperative day.

All the cases are investigated for haemoglobin and packed cell volume every day to detect any drop in the levels. The same are done at every $>300 \mathrm{~mL}$ collection into the drain container. Any drop in the $\mathrm{Hb}$ and PCV detected along with consistent fall in the BP and tachycardia, not corrected by IV fluids, are given blood transfusions with compatible whole blood till preoperative or more Hb levels and improved BP and Pulse are achieved. The transfusions are given to avert further haemodynamic instability.

The patients who have drop in Hb, PCV levels less than the mean levels and patients with preoperative $\mathrm{Hb}$, PCV levels more than mean are analysed as to how many of them are requiring blood transfusions to restore normal haemodynamic status.

The statistical tests applied to the study results are Chisquared test and $\mathrm{P}$ value and analysis is done to know the significance of the blood transfusions to avert the deterioration of haemodynamic status in the cohort with more than and below mean $\mathrm{Hb}$ levels, by applying chi-square test and the $P$ value.

\section{RESULTS}

Each patient in our study group is monitored with continuous recording of Pulse, $\mathrm{BP}$ and $\mathrm{Hb}$ and PCV everyday and/or for every collection of $\geq 300 \mathrm{~mL}$ blood into the suction drain container. The indication for blood transfusion is deteriorating haemodynamic status. The further monitoring is not done to avoid patients developing poor general condition with further deterioration without blood transfusions. The patients who had a drop in $\mathrm{Hb}$ and PCV levels, less than mean were 98 out of 168 cases. For the 98 cases, the IV fluids could not restore the expected Pulse and BP. The cases requiring blood transfusion are in both above mean (5) and below mean groups, more so in below mean (93) group. Blood transfusions were started with compatible whole blood to avert further haemodynamic instability. All the cases who have received postoperative blood transfusions could regain mean pulse (without tachycardia), $\mathrm{BP}, \mathrm{Hb}$ and PCV; 11 cases required 2 blood transfusions to restore and maintain normal haemodynamic status in which though the drain was removed, soakage at the drain site is seen for another two days. All these cases which required blood transfusions required two more days to start on weight bearing.

\section{Analysis of Results}

In the study group of 168 patients, there are 97 male patients and 71 female patients.

The mean $\mathrm{Hb}$ level is 10.29175 gm\%. There were 110 cases with above mean Hb levels and 58 cases with below mean. The mean PCV of $29.83 \%$ is observed in the study group. The mean systolic pressure recorded is $138.96 \mathrm{mmHg}$. The standard deviation is 0.1558 .

All the surgeries were done under tourniquet control, the intraoperative blood loss is nil. The tourniquet is released after the pressure bandage was applied.

The postoperative highest average blood loss on day one is $380 \mathrm{~mL}$ and on day two is $160 \mathrm{~mL}$ collected into the drain container. 
The mean fall in BP is $38.371 \mathrm{mmHg}$ in the postoperative period. The mean pulse rate recorded is 94.673 per minute. The mean $\mathrm{Hb}$ drop is seen by $3.124 \mathrm{gm} \%$. In the postoperative period, 70 cases remained with above mean $\mathrm{Hb}$ levels and 98 cases with below mean. The mean drop in the PCV is $11.954 \%$.

The study group has shown consistent tachycardia and hypotension with drop in $\mathrm{Hb}$ below $9 \mathrm{gm} \%$ and PCV below $29 \%$.

Out of 168 patients in study group, requirement for blood transfusion is analysed as given in the results with 93 cases requiring transfusion in the below mean group along with tachycardia and fall in BP and 5 cases requiring transfusion in the above mean group with fall in BP and tachycardia. All together the blood transfusion in the above mean $\mathrm{Hb}$ level patients has become necessary in $2.9 \%$ of cases and in below mean $\mathrm{Hb}$ for $55.35 \%$ of cases, and overall blood transfusions averted deterioration of haemodynamic status in $58.3 \%$ of cases.

\begin{tabular}{|c|c|c|c|}
\hline \multicolumn{4}{|c|}{ Results } \\
\hline & $\begin{array}{c}\text { Pre-0p } \\
\text { HB }\end{array}$ & $\begin{array}{c}\text { Post-0p } \\
\text { HB }\end{array}$ & $\begin{array}{c}\text { Blood } \\
\text { Transfusion } \\
\text { Requirement }\end{array}$ \\
\hline $\begin{array}{c}\text { Above Mean } \\
\text { HB }\end{array}$ & $110(65.5 \%)$ & $70(41.6 \%)$ & $5(2.9 \%)$ \\
\hline $\begin{array}{c}\text { Below Mean } \\
\text { HB }\end{array}$ & $58(34.5 \%)$ & $98(58.3 \%)$ & $93(55.35 \%)$ \\
\hline $\begin{array}{c}\text { Column } \\
\text { Totals }\end{array}$ & 168 & 168 & $98(58.3 \%)$ \\
\hline
\end{tabular}

The chi-square statistic is 92.3528. The p-value is $<0.00001$. The result is significant at $\mathrm{p}<.05$

Table 1. Haemoglobin Levels- Pre-Operative, PostOperative and Requirement of Blood Transfusions

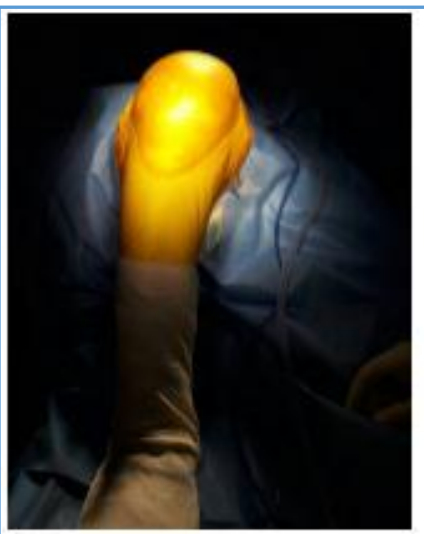

Skin to be incised

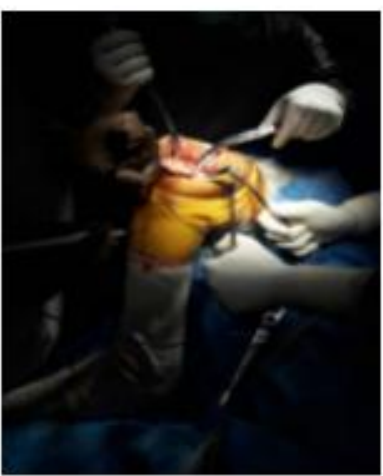

Tibial cut

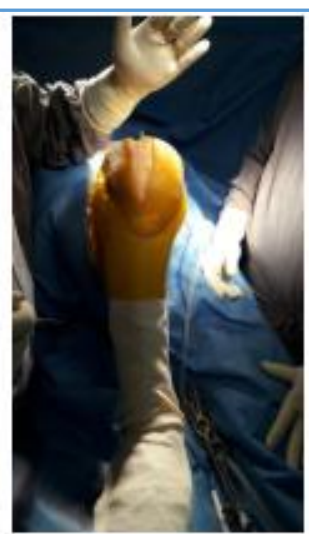

Skin incision

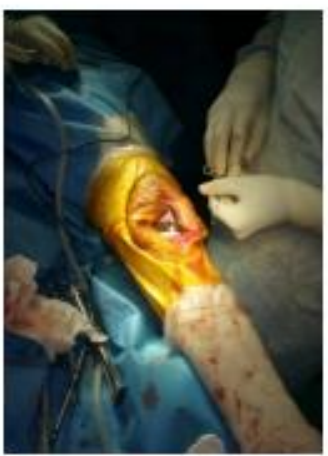

Closure

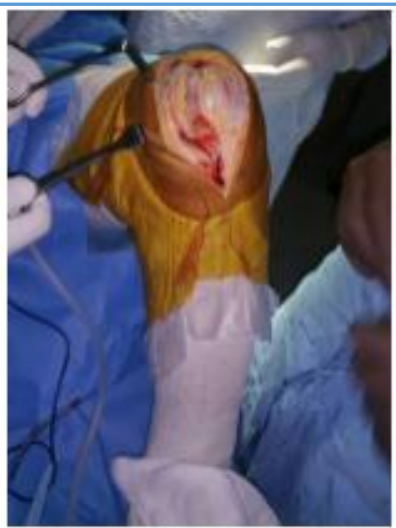

Arthrotomy

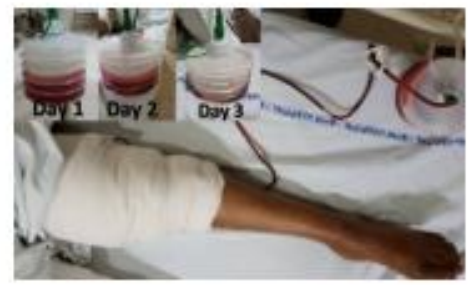

Drain collection

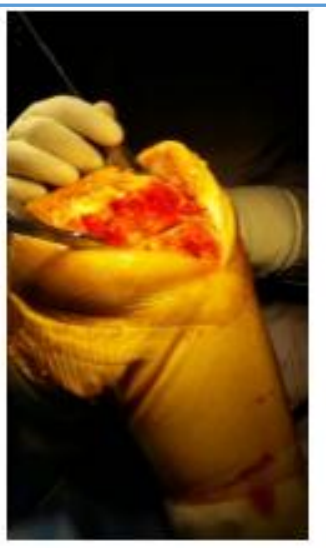

Femoral cut

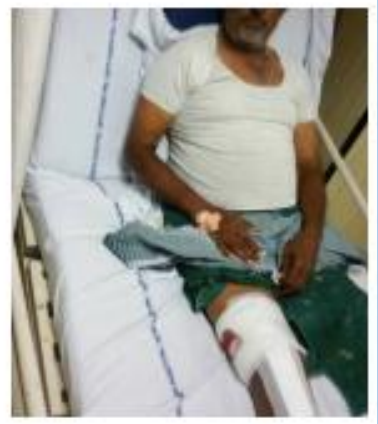

Drain site bleed

Figure 1. TKA and Blood Loss

\section{DISCUSSION}

The soft tissue dissection done for Total Knee Arthroplasty is the main source of blood loss. Adding to that, there are many factors that can cause more blood loss, viz. Sex of the patient, Hypertension, Anticoagulants given postoperatively. Our study has been done with cases undergoing TKA with midline incision, medial parapatellar arthrotomy and equal bone cuts for PS design implant. Another source of bleeding is the drain site. The trimming of patella is also a source of bleeding.
Entire soft tissue which was dissected, trimming of patella and drain site are the sources from which bleeding can occur postoperatively. The pressure dressing done postoperatively to certain extent can control the bleeding. The blood loss even though not having much difference in terms of quantity is able to produce haemodynamic changes. The changes which could not be averted by IV fluids alone are showing further deterioration in terms of fall in BP, pulse, drop in $\mathrm{Hb}$ and PCV 
levels. At this point of time, only blood transfusions can restore normal haemodynamic status.

\section{CONCLUSION}

We would like to conclude that Total Knee Arthroplasty is an elective surgery with a potential to cause more than $600 \mathrm{~mL}$ of blood loss. The haematocrit changes seen postoperatively are dependent on the haemodilution, going by the drop in $\mathrm{Hb}$ and PCV seen in both groups undergoing the same surgery with same indication, same approach, same surgeon and implant, even when the $\mathrm{Hb}$ and PCV levels are normal. The clinical improvement should be the benchmark in opting for blood transfusion with careful monitoring of the general condition. There is an inherent loss of blood into tissue planes, which can alter the haemodynamics with unseen blood loss.

\section{REFERENCES}

[1] Prasad N, Padmanabhan V, Mullaji A. Blood loss in total knee arthroplasty: an analysis of risk factors. Int Orthop 2007;31(1):39-44.

[2] Sehat KR, Evans R, Newman JH. How much blood is really lost in total knee arthroplasty? Correct blood loss management should take hidden loss into account. Knee 2000;7(3):151-5.

[3] Berman AT, Geissele AE, Bosacco SJ. Blood loss with total knee arthroplasty. Clin Orthop Relat Res 1988;234:137-8.

[4] Liu D, Dan M, Martos MS, et al. Blood management strategies in total knee arthroplasty. Knee Surg Relat Res 2016;28(3):179-87.

[5] Dan M, Liu D, Martos SM, et al. Intra-operative blood salvage in total hip and knee arthroplasty. J Orthop Surg (Hong Kong) 2016;24(2):204-8. 